\title{
Who Captures Value in Global Supply Chains? Case Nokia N95 Smartphone
}

\author{
Jyrki Ali-Yrkkö • Petri Rouvinen • Timo Seppälä • \\ Pekka Ylä-Anttila
}

Received: 5 September 2010 / Revised: 13 January 2011

Accepted: 29 April 2011/Published online: 31 May 2011

(C) The Author(s) 2011. This article is published with open access at Springerlink.com

\begin{abstract}
Available statistics reveal little about the economic consequences of the increasing global dispersion of production processes. To investigate the issue, we perform grass-roots investigative work to uncover the geography of the value added for a Nokia N95 smartphone circa 2007. The phone was assembled in Finland and China. When the device was assembled and sold in Europe, the value-added share of Europe (EU-27) rose to 68\%. Even when it was assembled in China and sold in the United States, Europe captured as much as $51 \%$ of the value added, despite of the fact that it played little role in supplying the physical components. Our analysis illustrates that international trade statistics can be misleading; the capture of value added is largely detached from the flow of physical goods. Instead, services and other intangible aspects of the supply chain dominate. While final assembly - commanding $2 \%$ of the value added in our case-has increasingly moved offshore, the developed countries continue to capture most of the value added generated by global supply chains.
\end{abstract}

Keywords global supply chains $\cdot$ international trade $\cdot$ value capture $\cdot$ Nokia $\cdot$ mobile phones

JEL Classification F $14 \cdot$ F $23 \cdot$ L $22 \cdot$ L 23

J. Ali-Yrkkö • P. Rouvinen $(\bowtie) \cdot$ T. Seppälä $\cdot$ P. Ylä-Anttila

ETLA, The Research Institute of the Finnish Economy, Lönnrotinkatu 4 B, 00120 Helsinki, Finland e-mail: pro@etla.fi

J. Ali-Yrkkö

e-mail: jay@etla.fi

T. Seppälä

e-mail: tse@etla.fi

P. Ylä-Anttila

e-mail: pya@etla.fi 


\section{Introduction}

In high-income countries, decision-makers and experts alike express their concern regarding production moving to lower-cost locations. Our illustration in this paper suggests that commonly employed measures exaggerate the issue to the extent that some aspects may even be illusory.

We agree with the theoretical argument of Grossman and Rossi-Hansberg (2008, p. 1978) that "Revolutionary advances in transportation and communications technology have weakened the link between labor specialization and geographic concentration, making it increasingly viable to separate tasks in time and space... The result has been a boom in "offshoring" of both manufacturing tasks and other business functions." We demonstrate, however, that value capture - the ultimate variable of interest for both businesses and countries - is considerably less dispersed than tasks within a supply chain.

Due to limitations regarding the available statistics, we resorted to grass-roots investigative work to uncover the geography of value added for the Nokia N95 smartphone circa 2007. We find that value capture is increasingly detached from the flows of physical intermediate and final goods. Instead, in-house and market services and various forms of intangible assets command the lion's share of value added (and thus income and profits earned). Even if final assembly has largely moved offshore, the developed countries continue to capture most of the value added generated globally: even for a "made in China" smartphone exported for sale in the US, we find that Europe (EU-27) still captures half of the value added.

Linden et al. (2009), who study the supply chain of Apple's iPod digital music player in 2005 , is the most relevant predecessor of our work. They conclude that even though the iPod was assembled in Asia, Apple's American workers and shareholders predominantly reaped the benefits. They also emphasize that innovation matters; the greatest value tends is owned by companies and locations providing critical differentiated inputs. Finally, they highlight the fact that international trade statistics can mislead as much as inform. All of these findings are echoed in our work.

Our approach and method closely resemble those of Linden et al. (2009). Besides obvious differences in terms of the industry, product, and point in time, our analysis is more detailed in several regards. Furthermore, our analysis focuses on value added (rather than gross margin). Our most important extension concerns the geographical breakdown of value added: we go beyond headquarters locations and allow for the generation of each component's value added in multiple locations and functions. To our knowledge, this is the first paper to examine global supply chains with regard to value added in such detail.

\section{Context}

The telecommunications industry typically consists of the following: network infrastructure equipment and its operation, end-user access (terminals, handsets, and portals), and digital content and services. Since the early 1990's, there has been a convergence of the telecommunications industry with closely related industries, particularly information technology (computers and their data networks, including the Internet) and content provision of various types, particularly radio, TV, and recorded audio and video.

Our case study of the Nokia N95 smartphone addresses one aspect of the telecommunications industry; the primary function of a phone is to provide a physical end-user access point to wireless voice and data networks and their services. As the phone in 
question was introduced at a time when the convergence mentioned above had progressed substantially, it embeds dozens of non-communication functionalities.

Advances in information and communication technology (ICT) have had an important enabling role in the geographic dispersion of production processes. Furthermore, ICT industries are themselves among the most dispersed major industries globally, which relate to the exceptional modularity of basic designs, especially for personal computers. While the industry's internal division of labor and geographic dispersion has not progressed as far for mobile phones as it has for PCs, it should be noted that our case considers an industry that has progressed further in geographic dispersion than many others.

Upon its announcement in 26 September 2006, the N95 was Nokia's flagship product. It was one of the first "all-in-one multimedia computers" having the size and weight of a standard phone. The N95 supported the latest high-speed mobile telephone protocols; it was also equipped with $\mathrm{WiFi}$ for long-range and Bluetooth for short-range data communications. It integrated GPS navigation, an MP3 player, an FM radio, and two video/still cameras, and it supported multiple email, messaging, and internet protocols. With its cameras, color display, and multiple speakers, the $N 95$ recorded and played back audio, video, and images with ease. Preinstalled software included a calculator, a calendar, and a dictionary, and - as with any computer - further software could be installed. The phone was actively marketed as an access point to the Internet services of Yahoo!, Amazon, and Flickr. The aforementioned convergence in industries would have been complete, if only the phone had supported the viewing of over-the-air television broadcasts. This omission was not, however, attributable to Nokia, but was rather related to the (still) lacking standards and unresolved intellectual property rights issues. Commercially, the N95 was a success: some ten million, highly profitable copies were sold worldwide.

\section{Sources}

Our analysis is based on five sources. First, in August 2008, with the help of two engineering experts, we physically took apart a fully-functioning N95 and examined each of its approximately 600 individual components. Second, we accessed public (particularly Internet searches) and private (direct contacts with various companies and individuals across the supply chain) information to obtain an idea of the direct (primarily coding for software and manufacturing/assembly for hardware) and indirect (R\&D, design, and various supporting functions) value added of each component. Third, we purchased a standard "teardown" report of the component composition of the N95 (Portelligent 2007), which also included estimates of factory prices and vendors by component. ${ }^{1}$ Fourth, armed with the knowledge gathered in the previous steps, we collected further qualitative and quantitative information (and confirmed the validity of the rest of the data) via interviews with sixteen industry experts working currently or previously in various roles in the mobile handset supply chain. ${ }^{2}$ Fifth, we examined financial reports and press releases of the companies involved and those of their direct competitors. We particularly exploited the

\footnotetext{
${ }^{1}$ The teardown report of Portelligent was acquired in September, 2008. We have also reviewed teardowns of other companies such as iSuppli.

${ }^{2}$ Due to the sensitivity of the topic, we had to assure full anonymity of our interviewees. The interviews were conducted between January 2009 and March 2010 and were semi-structured with questions that varied between interviewees depending on their position in the supply chain.
} 


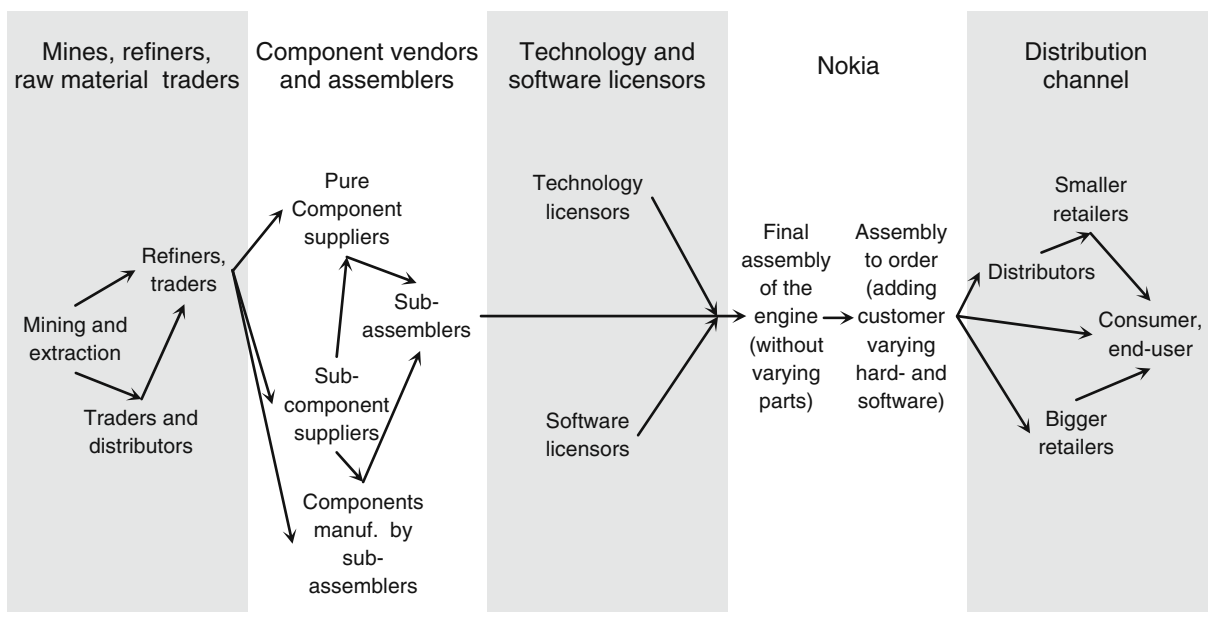

Fig. 1 A stylized supply chain of the Nokia N95

differences in reporting in various geographies and officially required further information, such as 20-F reports in the United States.

\section{The supply chain}

In our terminology, a supply chain refers to the global flows of intermediate goods and services (both those provided in-house and those purchased from outside vendors) involved in providing goods and services for final consumption. In each step, the vendor employs inputs, conducts its own value adding activities, and transfers its output to the other participants in the supply chain. The sum of all value adding activities equals the final retail price of the phone (before any applicable taxes are added).

Figure 1 represents a stylized supply chain for the Nokia N95. In the case of tangible components, typically four to eight layers exist between the assembly and the extraction of metals and minerals from the earth's crust (Nokia 2009). All components embed intangible assets in some form and conform to one or more industry standards. In the case of licensed or purchased embedded and standalone software, the flows cannot be readily mapped in a similar manner, but typically, fewer intermediate layers exist.

In Fig. 1, the actors in the supply chain of the N95 are categorized into five groups: mines and refiners, component vendors and sub-assemblers, software and technology providers and licensors, final assembly by Nokia, ${ }^{3}$ and wholesale and retail distribution by telecommunication network operators and/or general traders.

The flow in Fig. 1 is as follows. The still raw but now purified outputs of miners/refiners are turned to sheets of metal and other elementary processed goods that are traded to parts and components vendors. These vendors in turn deliver to sub-assemblers (which may in turn deliver to other sub-assemblers) feeding the final assembler. Some of the intangibles, to the extent that they are not embedded in and bundled with physical components, are

\footnotetext{
${ }^{3}$ Unlike some of its competitors, Nokia maintains significant in-house manufacturing and assembly capacity; in 2007 , Nokia outsourced $20 \%$ of the total assembly of its phones (SEC 2007, p. 36). All final assembly of the N95 was done by Nokia itself.
} 
licensed in a "pooled" form as parts of industry standards. Standalone software is acquired as necessary. Depending on the market, Nokia's direct customers are typically distributors (who in turn supply wholesalers and retailers) or operators. In both cases, the cooperation and support of the operators is vitally important in reaching the end-user.

\section{Value added by actor}

Let us first consider the direct components, parts, sub-assemblies, software, and licenses of the $N 95$ (the bill-of-materials). We first consider the actual sales prices (the gross value) ${ }^{4}$; but in later sections, we consider the first-tier suppliers on a value-added basis.

As shown in Table 1, the direct bill-of-materials amounts to approximately $€ 200$. It should be noted, however, that Nokia is a major holder of intellectual property rights (IPRs) regarding GSM/WCDMA cellular communication standards, and it does not pay licensing fees to itself. Furthermore, cross-licensing is quite common within the industry, in which case fees paid do not reflect the full value of the employed IPRs. For a company without its own employable/tradable IPRs, licensing fees could, in our view, be more than double those presented in Table 1.5 Apart from licensing fees, the most costly components of the phone are the processors, other integrated circuits, and the large color display.

The main integrated circuits of the N95 were provided by Nokia's long-time ally Texas Instruments (US). The display and the most expensive memory chips were obtained from Samsung (South Korea). On the semiconductor side, the main European companies involved were NXP Semiconductor (the Netherlands), STMicroelectronics (Switzerland), and Cambridge Silicon Radio (the UK).

As shown in Table 1, the licensing fee for the Symbian operating system was approximately $€ 3$. According to Nokia, the company paid less than $3 \%$ aggregate license fees on its WCDMA handset sales (based on Nokia's 12 April 2007 press release). On the basis of our interviews, we use $2.9 \%$ of Nokia's $€ 467$ factory price of the N95, i.e., $€ 13.5$. Besides Nokia, Qualcomm (US), Motorola (US), and Ericsson (Sweden) are among the major WCDMA IPR holders. In addition to the operating system and the telecommunication air interface, Nokia paid fees for, e.g., the inclusion of Adobe Acrobat Reader, RealPlayer, and Zip Manager. We estimate that in total, this software was responsible for $0.9 \%$ of Nokia's sales price, i.e., $€ 4.2$. The total cost of separately licensed intangibles and software was $€ 21$.

The approximately $€ 200$ listed in the bill-of-materials accounts for the purchases of Nokia from upstream vendors as inputs for the final assembly of the N95. It reflects the total value added of all the first-tier vendors and their suppliers (the second- and subsequent-tier vendors). Below, we analyze the value added by Nokia and the distribution channel.

\footnotetext{
${ }^{4}$ Throughout the paper, we refer to the unbundled and unsubsidized official retail price without including any applicable taxes and excluding any additional products and services purchased. Mobile phones' sales margins vary considerably and are difficult to estimate in many markets due to various types of tie-ins with subscriptions and other services.

${ }^{5}$ The Economist (28 Apr. 2007, p. 8) notes that "ABI research estimates that just four firms own almost $60 \%$ of the patents in $3 \mathrm{G}$ technology, pushing licensing rates as high as $28.5 \%$ of the cost of equipment." In this quote, it is somewhat unclear what is included in the licensing fees and what is the denominator, but even a conservative interpretation of this quote would suggest that, for an a priori industry outsider, licensing fees might have been manifold as compared to those listed in Table 1. In our view, the figure suggested in the Economist is somewhat exaggerated.
} 
Table 1 The bill of materials (BOM) of the Nokia N95 in 2007

\begin{tabular}{lrr}
\hline Description & \multicolumn{1}{c}{$\%$} \\
\hline Processors & 34.3 & $17.3 \%$ \\
Display & 21.6 & $10.9 \%$ \\
Main camera module (5 million pixels) & 16.5 & $8.3 \%$ \\
Memories & 14.5 & $7.3 \%$ \\
Battery pack & 3.0 & $1.5 \%$ \\
Video conference camera (VGA) & 1.2 & $0.6 \%$ \\
Other integrated circuits (excl. processors and memories) & 31.5 & $15.9 \%$ \\
Mechanics & 18.7 & $9.4 \%$ \\
All other hardware inputs & 21.1 & $10.6 \%$ \\
BOM (excl. supporting material, license fees and final assembly) \\
Supporting material & 162.4 & $81.8 \%$ \\
BOM (excl. license fees and final assembly) & 15.5 & $7.8 \%$ \\
GSM/WCDMA license fees & 177.9 & $89.6 \%$ \\
Symbian operating system & 13.5 & $6.8 \%$ \\
Other license fees & 3.0 & $1.5 \%$ \\
BOM (excluding final assembly) & 4.2 & $2.1 \%$ \\
\hline
\end{tabular}

Source: ETLA

For each company in the supply chain of the N95, we derived the ratio of value added to net sales or the value added margin at the firm level. For the most part, we then equated this with the component-level value added margin. ${ }^{6}$

For the distributors, wholesalers, and retailers, the value added margin and the sales margin are almost identical. Retailers' sales margins on high-end mobile phones are somewhat lower than is usual in the electronics sector, $10-12 \%$ of the final sale price, leading to an estimated value added of $€ 60.1$ by the retailer. The distributors'/wholesalers' margins are 3.3-4.5\%, suggesting an estimated value added of $€ 19.1$.

Subtracting all downstream costs from the price Nokia sells the phone to the distribution channel yields its own value added, €269. This value added is allocated to direct and indirect in-house labor costs (e.g., in its manufacturing/assembly, innovation, advertising, design, marketing, financial, legal, and management functions), depreciation of tangible and intangible assets, investments, and operating profit. It also includes some aspects of outsourcing, which we were unable to separate from Nokia's internal functions: purchases of "billable hours", some R\&D and software sub-contracting, outbound logistics, and certain externally provided warranty and other services.

\footnotetext{
${ }^{6}$ A company's value added is equal to the sum of its operating profit, depreciation, and labor costs. For the few companies that conform only to US GAAP accounting principles, labor costs are unavailable. For these firms, we assume the margins to be the same as for their nearest competitors. Thus, for example, in the case of the charger included in the sales package of the N95: the factory price of the charger is $€ 1.1$, and it is supplied by Astec (US), which is a part of the Emerson Network Power group using US GAAP. Its direct competitor Salcomp Oy (Finland)_-globally the leading mobile phones' charger vendor-follows IFRS. In its 2007 financial statement, Salcomp's value added margin was 23.3\%. Thus, we estimate Astec's value added to be approximately $€ 0.3$. Similarly, in the case of Texas Instruments (US), we employ the average of the value added margins of the three competitors it identified in its 2007 Form 10-K report (pp. 3-4) required by the US Securities and Exchange Commission, i.e., NXP (the Netherlands), Infineon Technologies AG (Germany) and STMicroelectronics (Switzerland).
} 
Careful studies of industry sources and our interviews suggest that the final assembly/ manufacturing cost of the $N 95$ is $€ 11.5$, i.e., $2 \%$ of the pre-tax final sales price. ${ }^{7}$ Thus, even if the final assembly is the essential part of the supply chain that meets the eyes of laymen (not least because of the "Made in ..." labeling found on manufactured goods), the value added it commands is quite low.

Table 2 presents a value-added breakdown of the N95's pre-tax retail price of $€ 546$ : Nokia captures $50 \%$ of the value, first-tier hardware vendors $11 \%$, first-tier (external, noncross-licensed) software/intangible vendors 3\%, second- and higher-tier vendors (vendorsof-vendors) $19 \%$, distribution/wholesale $3.5 \%$, and retail $11 \%$.

\section{Value added by location}

Table 2 provides a global breakdown of value added by the actors' major categories. Because the gross domestic product can be measured as the sum of the values added by all activities in a given country, national interest is based on where the value capture takes place. ${ }^{8}$ Determining this is somewhat difficult, as companies are reluctant to reveal the geography of their operations even at the firm level (let alone at the level of a specific commercial offering). With some detective work, we can nevertheless make reasonably accurate estimates, at least as far as broader geographical regions are concerned.

The value capture of in-house indirect inputs, such as the role of general management and brand, and re-usable tangible and intangible assets (such as designs copied from previous or contributing to future models) are particularly tricky to allocate per phone and especially across geographies. Furthermore, we do not observe all actors and functions involved. Thus, In Table 3 we consider five alternatives in constructing the geographical breakdown:

- Our baseline method, in Column A, allocates the value added to the headquarters location of each participant in the supply chain. This tends to over-estimate the role of developed countries and regions.

- Our second method, in Column B (see Eq. 4 in Appendix 1), assigns the value capture solely on the basis of the locations of the production factors (physical capital, labor, and R\&D). This does, for instance, implicitly assume that the general management or corporate brand has no specific role in the value capture tending to under-estimate the role of developed countries and regions.

- The third alternative, in Column C, is an intermediate method between A and B: it is assumed that, in the case of each participant, $10 \%$ of the value capture takes place at the headquarters location and $90 \%$ is based on to the actual location(s) of the participant's factors of production.

- Individuals and organizations in various locations have different productivities. Thus, their ability to capture value may vary. Column D replicates Column B, with the exception that it attempts to correct for this fact using multifactor productivity differences between regions (see Eq. 6 in Appendix 1).

\footnotetext{
${ }_{7}^{7}$ In addition to direct labor costs, our estimate includes factory management and other indirect labor and capital costs.

${ }^{8}$ Obviously employment is also of considerable national interest. We do not consider employment effects in this paper.
} 
Table 2 The value added breakdown of the Nokia N95 listed by supply chain participant, $\%$

\begin{tabular}{ll} 
Suppliers of material inputs & $11 \%$ \\
Software and other companies selling licenses & $3 \%$ \\
Nokia & $50 \%$ \\
Distributors & $3 \%$ \\
Retailers & $11 \%$ \\
Unaccountable inputs & $3 \%$ \\
Vendors of vendors & $19 \%$ \\
\hline
\end{tabular}

Source: ETLA

- Our preferred estimation method (Column E) combines Columns C and D. Thus, in the case of each participant, $10 \%$ of the productivity-adjusted value capture occurs at the headquarters location and $90 \%$ at the actual location of the production factors.

In a sense, $\mathrm{A}$ and $\mathrm{B}$ constitute the lower and upper bounds for Europe, $\mathrm{C}$ and $\mathrm{D}$ refine certain aspects, and E provides our preferred estimate of the geography of the value capture.

It should be noted that the first five rows in Table 3 (Finland ... Other countries) do not fully reflect the value captured by each location simply because the next four rows (Other countries ... The country of final assembly) have not been allocated accordingly. While we have a sense of the geography of vendors-of-vendors and we can make educated guesses regarding the inputs they provide, we cannot discriminate between unrecognized vendors (Unaccounted inputs), as the level of detail in our data is not comparable to our understanding of Nokia and its first-tier suppliers. With these caveats, we adopt our "rock-bottom" estimate E from Table 3 and split the value added of the unaccounted inputs and vendors-of-vendors to geographies with the assumptions discussed below (see also the notes to Table 3).

The geographical allocations of the country of final sales and final assembly depend on the specific case. For instance, for an N95 assembled in Finland (Salo) for the German market, an extra $2.1 \%$ would go to Finland and an extra $14.5 \%$ to Germany (Other EU-27); for an $N 95$ assembled in China (Beijing) for final sale in the United States, the outcome would be different. We considered how the two cases (from Finland to Germany and from China to the United States) are recorded in international goods trade statistics on the basis of gross value, and how the value added on a geographical basis differs from that (Tables 4 and 5). ${ }^{9}$

\subsection{Further considerations}

Our best estimate is that over the life cycle of the $N 95,55 \%$ of the value added was captured by EU-27 countries, taking into account both assembly locations and all countries of final sale (Table 5, bottom). Even when the final assembly occurred in China and the

\footnotetext{
${ }^{9}$ In 2007, the basic principle applied by Nokia was that smartphones intended for the European market were assembled in Europe, and smartphones intended for the Asian market were assembled in Asia. To our knowledge, smartphones intended for the US market were mainly assembled in Asia. Thus, using these three principles as our guidelines, the potential combinations are as follows: assembled in EU and sold in EU; assembled in EU and sold in other countries; assembled in Asia and sold in Asia; assembled in Asia and sold in North America; and assembled in Asia and sold in other countries. As a robustness check (Appendix 2), we changed the assumptions and re-calculated the geographical allocations.
} 


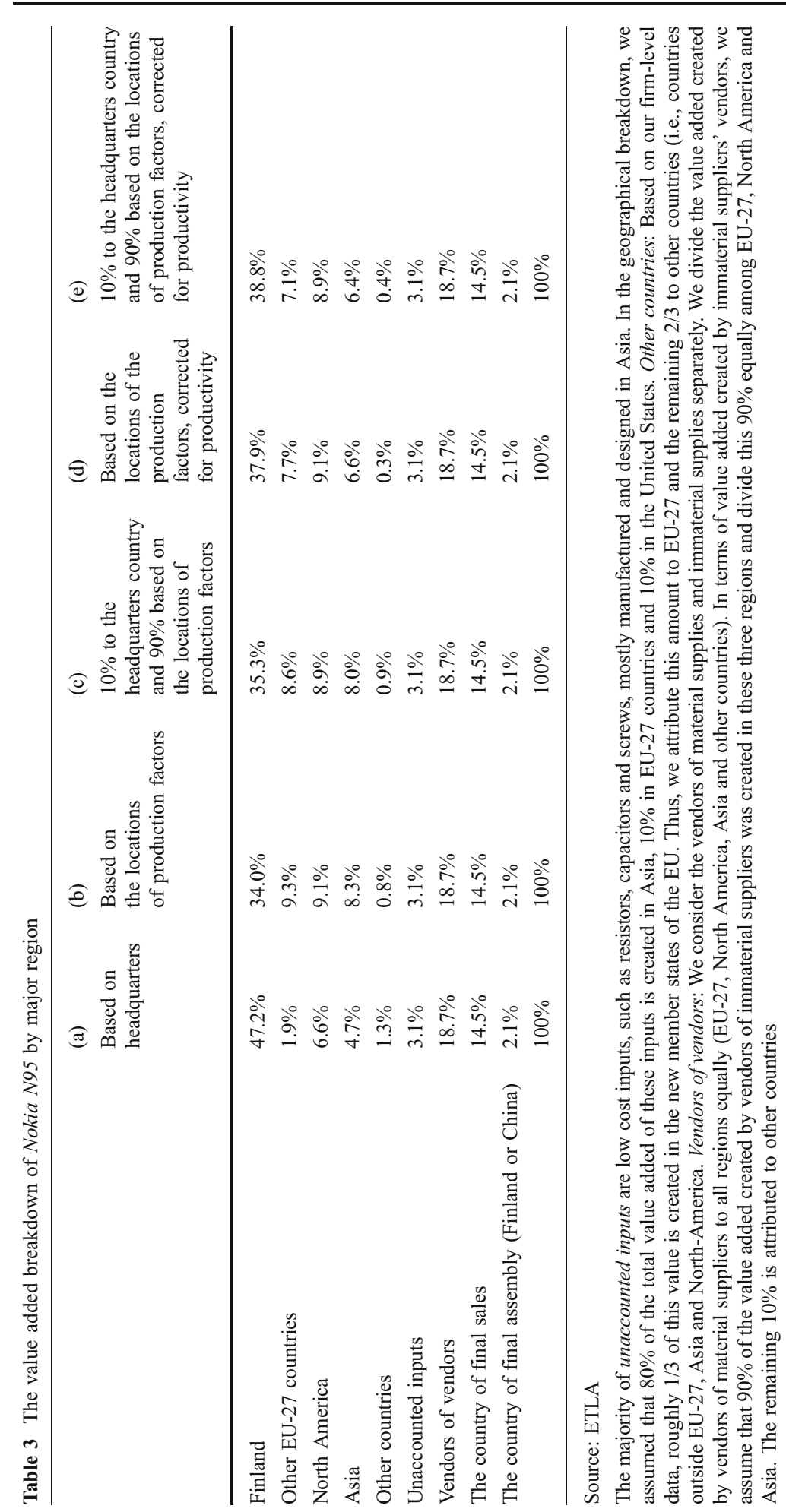


Table 4 The geography of the gross value in two cases of the N95 as recorded in international goods trade statistics.

Exports from Finland to Germany
Exports from China to the US

Assembly in Finland, final sale in

$€ 467$

Germany

Assembly in China, final sale in the US

$€ 467$

final sales occurred in the United States, EU-27 countries captured 51\% of the value added (Table 5, middle), despite the fact that the phone was Made in China.

How is it possible that EU-27 countries capture so much of the value based on such an apparently minor role? This occurs simply because Finland and other EU-27 countries were dominant in the branding, development, design, and management.

Table 6 summarizes some of the above findings. While the final assembly is the main step in the physical incarnation of the product, this stage only commands $2 \%$ of the overall value added. However, the distribution channel, and its ultimate retail loop in particular, captures a large share of the value added - many times more than the final assembly.

We referred above to international goods trade statistics and ignored service trade statistics. On the basis of the supply chain's geography and the assembly volume of the N95 in Nokia's Beijing plant, we estimate that service exports from Finland to China in 2007 were approximately $€ 0.8$ billion with respect to the N95. As recorded by Statistics Finland, however, the total service trade across all industries from Finland to China was $€ 0.6$ billion in 2007. Thus, the recorded overall figure does not account even for this one phone model, which in 2007 accounted for less than 1.5\% of all sold Nokia phones and less than $7.5 \%$ of all Nokia phone sales. ${ }^{10}$

In the above calculations, we assigned Nokia's operating profits to the headquarters location, which is consistent with prevailing national accounts practices. It does not suggest that Finns would "own" this part of the value added beyond their ownership of the company. Indeed, more than $90 \%$ of Nokia's stock is held abroad and profits earned belong ultimately to the shareholders, in this case primarily to US-based institutions. Any dividends paid to foreigners are appropriately recorded in cross-border financial flows. It turns out, however, that companies' purchases of their own shares are not appropriately recorded, which in the case of Finland inflates its current account surplus. Savolainen and Forsman (2010) note that Nokia's purchases of its own shares amounted to $€ 18.6$ billion in 2003-2008. In 2005, they amounted to 2.3\% of Finnish GDP.

Although our N95 analysis is a single case study, it is, based on our understanding, a typical case in the electronics industry. Furthermore, automobiles, textiles, and some other traditional industries do not appear very different. Even in industries that feature less geographical dispersion, dispersion is nevertheless increasing. In our opinion, broader conclusions can be legitimately drawn from our analysis.

\section{Conclusions}

Even though the location of the final assembly earns the "made in ..." label, the labeled country may command only a few percent of the supply chain's overall value added of an

$\overline{{ }^{10} \text { For a more general discussion }}$ on the globalization of trade in services, see Lejour and Smith (2008). 
Table 5 The geography of valued added in the two cases discussed in Table 4 and over the product's life cycle (accounting for both assembly locations and all final sales markets)

\section{Finland Other EU-27 Asia North-America Rest of the} countries

\begin{tabular}{llllll}
\hline Assembly in Finland, final sale in Germany & $41 \%$ & $27 \%$ & $13 \%$ & $14 \%$ & $5 \%$ \\
Assembly in China, final sale in the US & $39 \%$ & $12 \%$ & $16 \%$ & $28 \%$ & $5 \%$ \\
Both assembly locations, all markets & $38 \%$ & $16 \%$ & $18 \%$ & $17 \%$ & $11 \%$ \\
\hline
\end{tabular}

Source: ETLA

advanced industrial good. Unlike the apparent conclusions drawn from the cross-border flows of the related physical components and goods, developed countries continue to capture the lion's share of value added generated globally. Even for manufactured goods, most of the value added is captured by services (both in-house and those purchased from external vendors) and various forms of intangibles (including returns earned on various forms of intellectual property).

Our analysis has several broader implications. First, it highlights the irrelevance of the lingering manufacturing vs. services discussion. The recorded value added by manufacturing

Table 6 Breakdown of the phone's $€ 546$ ( $+\operatorname{tax})$ retail price circa 2007

\begin{tabular}{lll}
\hline Physical components & $€ 178$ & $33 \%$ \\
Processors & $€ 34$ & $6 \%$ \\
Other integrated circuits & $€ 32$ & $6 \%$ \\
Memories & $€ 15$ & $3 \%$ \\
Display & $€ 22$ & $4 \%$ \\
Main camera (5 mill. pixels) & $€ 17$ & $3 \%$ \\
Other physical components & $€ 59$ & $11 \%$ \\
Licenses and software & $€ 21$ & $4 \%$ \\
Nokia's value added & $€ 269$ & $49 \%$ \\
Internal support functions & $€ 169$ & $31 \%$ \\
Operating profit & $€ 89$ & $16 \%$ \\
Final assembly & $€ 11$ & $2 \%$ \\
Distribution and retailing & $€ 79$ & $14 \%$ \\
Distribution & $€ 19$ & $4 \%$ \\
Retailing & $€ 60$ & $11 \%$ \\
\hline
\end{tabular}

Source: ETLA

The phone's $€ 546$ retail price is the unbundled and unsubsidized official retail price without the inclusion of any applicable taxes; it also excludes other products and services possibly purchased at the time of initial sale or later. Licenses include protocols, the operating system, pre-installed software etc. Nokia is a major intellectual property (IP) holder in this domain and does not pay fees to itself. Thus, the value of its own IP is not included here. Furthermore, non-monetary payments (e.g., cross-licensing) are not included here. For a firm without its own IP, licensing fees could be manifold; see the text for discussion. In addition to operating profit and the final assembly, Nokia's value added covers its innovation, advertising, design, marketing, legal, and management costs, as well as depreciation and investments. It also includes some aspects of outsourcing we were unable to separate from Nokia's internal functions: purchases of "billable hours", some R\&D and software sub-contracting, outbound logistics, and certain external warranty \& other services. Nokia's operating profit has been estimated on the basis of the overall operating profits of Nokia Multimedia in 2006 and 2007 by assuming that the profitability of the N95 was typical of a phone 
has a significant service component; most services need supporting physical infrastructure and complementing goods. The distinction between manufacturing and services is immaterial and should perhaps be laid to rest completely. Second, international commodity trade statistics that continue to record the gross values of cross-border goods flows can be highly misleading in economic analysis. Indeed, internationally concerted efforts should be taken to develop value added based trade statistics. While complementing the goods with service trade statistics and balance of payments information should help in principle, this does not currently appear to be the case in practice. Our crude estimates in the previous section suggest that service trade statistics and balance of payments information might be equally misleading, albeit for different reasons. Third, in many countries, national policy makers appear to have an obsession with having a certain national capacity of final assembly. This can hardly be justified by its role in national value added. This is not to say that final assembly has no importance, just that its national importance may relate more to its links with other functions in the supply chain.

Ultimately, nations compete for their citizens' high value adding roles in globally dispersed supply chains. For a given level of effort, the national objective is then to capture as much value and generate as much national wealth as possible. While China is determined not to remain a " $2 \%$ " assembly location and is rapidly extending its higher value adding functions, Europe and the United States retain many advantages in providing globally differentiating inputs.

Acknowledgements This research is a part of the ongoing collaboration between BRIE, the Berkeley Roundtable on the International Economy at the University of California at Berkeley, and ETLA, The Research Institute of the Finnish Economy. Part of the work was done within the European Commission project B2/ENTR/05/091-FC and was financed under the Competitiveness and Innovation Framework Programme (CIP) which aims to encourage the competitiveness of European enterprises.

Open Access This article is distributed under the terms of the Creative Commons Attribution Noncommercial License which permits any noncommercial use, distribution, and reproduction in any medium, provided the original author(s) and source are credited.

\section{Appendix 1}

To estimate the geographical breakdown of the value of the N95, we proceed as follows: The total value of the product $\mathrm{Y}$ is composed of the value added of all parts of the N95's supply chain or

$$
Y=\sum_{c=1}^{N} Y_{c},
$$

where

$Y \quad$ The total value of the N95

$Y_{c} \quad$ The value added of part $c$ of the supply chain.

The value added of each part $\left(Y_{c}\right)$ can be created globally. We assume that this total value added of each part is created in an area covering the home country (Finland), other European countries, North America and Asia, thus

$$
Y_{c}=Y_{c, D}+Y_{c, E}+Y_{c, N}+Y_{c, A}+Y_{c, O},
$$

where

$D$ Domestic (Finland)

E Europe (Other EU-27 countries) 


\section{$N$ North America \\ A Asia \\ $O$ Others}

Our data includes the value added of each part $\left(Y_{c}\right)$, but information regarding how this value added is created in different areas is not available. To estimate the value added of part $c$ created in each region $\left(Y_{c, D}, Y_{c, E}, Y_{c, N}, Y_{c, A}, Y_{c, O}\right)$, we proceed as follows:

We assume that the value added of part c captured in each region is created through factors of production. As is usual in the economic literature, we consider three factors of production: physical capital stock $(C)$, the size of the labor force $(L)$ and knowledge capital stock $(K)$. We assume that the effect of each production factor is the same as that of their elasticities of output. The previous empirical literature (including a number of studies) has estimated a Cobb-Douglas type of production function:

$$
Q=A C^{\alpha} L^{\beta} K^{\gamma}
$$

where $A$ is the multiplicative technology parameter.

Equation 3 is typically estimated in logarithm form. Thus, the parameters $\alpha, \beta$, and $\gamma$ are the elasticities of output $(Q)$ with respect to physical capital stock, labor and knowledge, respectively. In the majority of empirical studies, the estimated production function has included only two factors of production: physical capital and labor. Usually, the results of empirical studies show that the physical capital elasticity is approximately 0.4 and the labor elasticity is approximately 0.6 .

In studies, where knowledge capital is approximated using R\&D stock, the estimated knowledge capital elasticity typically varies between 0.05 and 0.25 (Hall 1993; Mairesse and Hall 1994; Harhoff 1998; Capron and Cincera 1998). In our calculations, based on these studies, we assume that this elasticity is 0.15 . However, most studies have not takes the double counting related to $R \& D$ into account. $R \& D$ investment also consists of investment in physical capital and labor, and these components are included in the regular production factors (Schankerman 1981; Hall and Mairesse 1996). Based on earlier literature, we know that approximately $50 \%$ of R\&D expenditures are labor costs (Hall 2009). Considering this, we modify the capital elasticity $(0.6)$ and labor elasticity $(0.4)$ as follows:

$$
\begin{aligned}
& \widehat{\alpha}=\alpha-0.5 \gamma \\
& \widehat{\beta}=\beta-0.5 \gamma
\end{aligned}
$$

Thus, our our corrected elasticities for capital, labor and R\&D are $0.325,0.525$ and 0.15 , respectively. We use these elasticities as the multipliers of the production factors.

We continue by calculating what share of each production factor is located in each region $R$ and then multiply each share by the elasticity of output. We then sum these values by region and obtain each region's share of value added (related to part $c$ ). Finally, we multiply this share by the value added of part $c\left(Y_{c}\right)$. The value added of part c created in region $R$, is calculated as follows:

where

$$
Y_{c, R}=\left(\frac{C_{R}}{C} \widehat{\alpha}+\frac{L_{R}}{L} \widehat{\beta}+\frac{K_{R}}{K} \gamma\right) Y_{c},
$$

$C_{r} \quad$ is the firm's physical capital stock in region $R$

$C$ is the sum of the firm's physical capital in all regions 
$L_{R} \quad$ is the firm's employment in region $R$

$L \quad$ is the sum of the firm's employment in all regions

$K_{R}$ is the firm's knowledge capital in region $R$

$K$ is the sum of the firm's knowledge capital in all regions,

Thus, for instance, the domestically created value added is calculated as follows:

$$
Y_{c, D}=\left(\frac{C_{D}}{C} \widehat{\alpha}+\frac{L_{D}}{L} \widehat{\beta}+\frac{K_{D}}{K} \gamma\right) Y_{c}
$$

Equations 4 and 5 implicitly assume that the total productivity is equal in each region. To take the regional productivity differences into account, we calculate the productivitycorrected value added of part $c$ created in region $R$ as follows:

$$
\widehat{Y}_{c, R}=\frac{\operatorname{MFP}_{R}\left(\frac{C_{R}}{C} \widehat{\alpha}+\frac{L_{R}}{L} \widehat{\beta}+\frac{K_{R}}{K} \gamma\right)}{\sum M F P_{R}\left(\frac{C_{R}}{C} \widehat{\alpha}+\frac{L_{R}}{L} \widehat{\beta}+\frac{K_{R}}{K} \gamma\right)} Y_{c} \quad R \in(D, E, N, A, O),
$$

where $M F P_{R}$ is the multi-factor productivity in region $R$.

Thus, for instance, the domestically created value added is calculated as follows:

$$
\widehat{Y}_{c, D}=\frac{M F P_{D}\left(\frac{C_{D}}{C} \widehat{\alpha}+\frac{L_{D}}{L} \widehat{\beta}+\frac{K_{D}}{K} \gamma\right)}{\sum M F P_{R}\left(\frac{C_{R}}{C} \widehat{\alpha}+\frac{L_{R}}{L} \widehat{\beta}+\frac{K_{R}}{K} \gamma\right)} Y_{c} \quad R \in(D, E, N, A, O)
$$

Operationalization of production factors

If component-level factors and factor shares are unavailable, we use firm-level information regarding the location of different factors. Firm-level data is based on the annual reports and websites of each vendor. We have operationalized variables as follows:

$C=$ Non-current assets or long-lived assets, depending on which was reported in 2007.

$L=$ The number of employees (in 2007).

$K=\mathrm{R} \& \mathrm{D}$ expenditure. We are unable to calculate $\mathrm{R} \& \mathrm{D}$-stock for each region. Therefore, we used R\&D expenditure for 2007.

In some cases, the reported regional breakdown of some factor is imperfect. In these cases, we read the entire annual report carefully and researched necessary information on the Internet to approximate the regional breakdown. For example, National Semiconductor (US) reports the regional breakdown of long-lived assets (Annual Report, p. 104) and employees (Annual Report, p. 12), but do not report the exact geographical breakdown of their R\&D expenditure. However, on page 21, the company reports that their principal research facilities are located in Santa Clara (US) and that they operate small design facilities in 13 other locations in the United States and 11 locations outside the US. Out of those 11 overseas R\&D units, approximately half are located in Asia and half in the EU-15 area. Based on these facts, we estimate that approximately $70 \%$ of R\&D is done in the U.S. and divide the remaining 30\% fifty-fifty between Europe (15\%) and Asia (15\%). 
Operationalization of multi-factor productivity (MFP)

We used value added-based MFP figures of the Electrical and Optical equipment and Post and Telecommunications industries reported by Inklaar and Timmer (2008). ${ }^{11}$ Using this database, the regional MFP's used in our estimations are as follows:

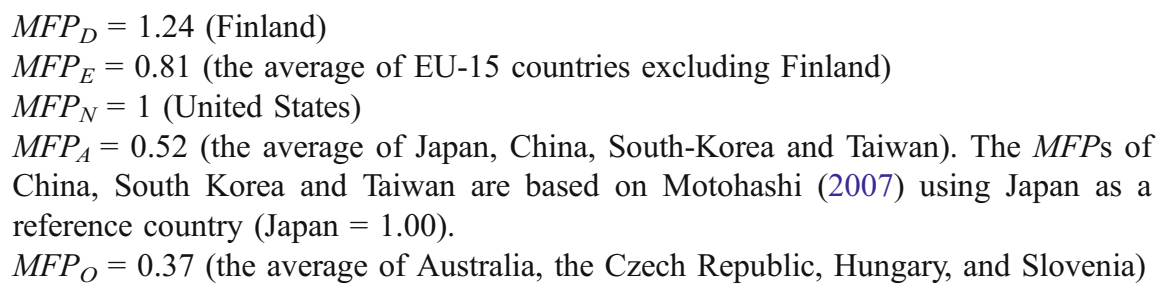

\section{Appendix 2}

To test to what extent our results depend on the assumptions we made related to the value added created by material suppliers' vendors, we recalculate the geographical breakdown of value added by changing these assumptions. One could argue that Asia's role in these upstream activities is greater than assumed in our basic calculations. Moreover, Australia, Russia and Africa are important raw material providers, and our basic assumptions potentially under-estimate the role of these regions in this regard. For these two reasons, we lower the share of the EU-27 countries to $10 \%$ and North America to $10 \%$ and raise the share of Asia to $50 \%$ and that of the other countries (including, e.g., Australia, Russia and Africa) to $30 \%$ of the value added created by vendors of vendors. We then re-calculate all potential combinations related to the final assembly location and the country of final sales. The results of this re-calculation show that our basic results are valid. On average, $52 \%$ of the total value added is captured in EU-27 countries, 14\% in North America, 22\% in Asia and $12 \%$ in the rest of the world.

\section{References}

Capron H, Cincera M (1998) Exploring the spillover impact on productivity of world-wide manufacturing firms. Annales d'Economie et de Statistique January-June (49-50):565-587

Economist (28 Apr. 2007) A world of connections. The Economist (cover story), vol 383

Grossman GM, Rossi-Hansberg E (2008) Trading tasks: a simple theory of offshoring. Am Econ Rev 98 (5):1978-1997

Hall BH (1993) Industrial Research during the 1980s: Did the rate of return fall? Brookings papers on economic activity microeconomics 2

Hall BH (2009) The financing of innovative firms. European Investment Bank Papers 14(2):8-28.

Harhoff D (1998) R\&D and productivity in german manufacturing firms. Econ Innovat New Tech 6(1):2949

Inklaar R, Timmer M (2008) GGDC productivity level database: international comparison of output, inputs and productivity at the industry level. EU KLEMS Working Papers 40

Lejour AM, Smith PM (2008) International trade in services-editorial introduction. J Ind Compet Trade 8(3/ 4):169-180. doi:10.1007/s10842-008-0037-y

$\overline{11}$ This data is downloadable at www.ggdc.net/databases/levels.htm 
Linden G, Kraemer KL, Dedrick J (2009) Who captures value in a global innovation network? The case of Apple's iPod. Commun ACM 52(3):140-144

Mairesse J, Hall BH (1994) Estimating the productivity of R\&D in French and U.S. manufacturing firms: an exploration of simultaneity issues with GMM. In: Wagner K, van Ark B (eds) International Productivity Comparisons. North-Holland, Amsterdam, pp 285-315

Mairesse J, Hall BH (1996) Estimating the productivity of research and development: an exploration of GMM methods using data on French and Unites States manufacturing firms. NBER Working Papers, 5501. National Bureau of Economic Research, Cambridge, Massachusetts

Motohashi K (2007) Assessing Japan's industrial competitiveness by international productivity level: comparison with China, Korea, Taiwan and the United States. In: Jorgenson DW, Kuroda M, Motohashi K (eds) Productivity in Asia: economic growth and competitiveness. Elgar, Cheltenham, pp 215-238

Nokia (2009) Supply chain. http://www.nokia.com/corporate-responsibility/supply-chain/overview.

Portelligent (2007) Nokia N95: GSM/EDGE 850/900/1800/1900MHz + WCDMA/HSDPA $2100 \mathrm{MHz}$ UMTS Cellular Phone

Savolainen E, Forsman P (2010) Osakkeiden takaisinostot kaunistelevat vaihtotasetta (in Finnish). Tieto \& Trendit 7. http://www.stat.fi/artikkelit/2010/art 2010-11-10 001.html

Schankerman M (1981) The effects of double-counting and expensing on the measured returns to R\&D. Rev Econ Stat 63(3):454

SEC (2007) FORM 20-F REPORT-Nokia Corporation. Securities and Exchange Commission, Washington 